\title{
3 Research Square \\ Early cardiac rehabilitation improved prognosis in patients with heart failure following acute myocardial infarction
}

He Cai

Jilin University

Pengyu Cao ( $\square$ caopy1979@outlook.com )

The Cardiovascular Center, The First Hospital of Jilin University https://orcid.org/0000-0003-05605159

\section{Wanqing Sun}

Chinese Academy of Medical Sciences \& Peking Union Medical College Fuwai Hospital

\section{Xinying Zhang}

jilin university

\section{Rongyu Li}

Jilin university

\section{Wangshu Shao}

Jilin university

Lin Wang

Jilin university

Lin Zou

Jilin university

Yang Zheng ( $\square$ zhengyanghappy07@sina.com )

Jilin university

\section{Research article}

Keywords: Cardiac rehabilitation, Cardio-respiratory fitness, Cardio-pulmonary exercise, Heart failure, Myocardial infarction, Percutaneous coronary intervention

Posted Date: September 14th, 2020

DOI: https://doi.org/10.21203/rs.3.rs-36808/v2

License: (c) (i) This work is licensed under a Creative Commons Attribution 4.0 International License. Read Full License 


\section{Abstract}

Background: Cardiac rehabilitation (CR) has been shown to improve exercise intolerance and QoL, and minimize re-hospitalizations in patients with congestive heart failure (CHF). However, studies on early CR in patients with acute myocardial infarction (AMI) who developed CHF following percutaneous coronary intervention $(\mathrm{PCl})$ are rare. The purpose of this study is to evaluate the effectiveness of early $\mathrm{CR}$ on patients with $\mathrm{CHF}$ after $\mathrm{AMI}$ following $\mathrm{PCl}$.

Methods: Two hundred thirty-seven patients who developed heart failure after AMI following PCI were enrolled. Patients were divided into heart failure with reduced ejection fraction (HFrEF) group $(n=55)$ and heart failure with mid-range ejection fraction (HFmrEF) group ( $n=182)$. Of the 237 patients, 78 (22 in HFrEF group and 56 in HFmrEF group) who accepted a two-week CR were further divided into two subgroups based on major adverse cardiovascular events (MACE). Key cardio-pulmonary exercise testing (CPX) variables that may affect the prognosis were identified among the CR patients.

Results: Early CR significantly reduced cardiac death in patients with $\mathrm{HFrEF}(18.2 \%$ vs. $60.6 \%, \mathrm{P}=0.02)$, and reduced re-hospitalization in patients with HFmrEF after AMI (3.6\% vs. 21.4\%, P=0.02). Serum potassium and $\mathrm{CR}$ ratio were independent risk factors for MACE in patients with both HFrEF and HFmrEF after AMI. In the CR group who developed MACE, there were more diabetics $(22.2 \%$ vs. $66.7 \%, P=0.035)$, with higher serum potassium $(3.96 \mathrm{mmol} / \mathrm{I}$ vs. $4.31 \mathrm{mmol} / \mathrm{l}, \mathrm{P}=0.043)$, and lower PETCO2 at ventilatory threshold (VT) $(P=0.016)$. PETCO2 at VT was an independent risk factor for re-hospitalization. The incidence of re-hospitalization was significantly lower when the PETCO2 at VT was greater than $33.5 \mathrm{mmHg}(0(0.00 \%$ vs. $6(13.64 \%), P=0.03)$.

Conclusions: Early CR reduced the incidence of MACE in patients with heart failure after AMI following $\mathrm{PCl}$. The PETCO2 at VT is an independent risk factor for re-hospitalization, and could be used as a key evaluating hallmark for early CR in patients who developed heart failure after AMI.

\section{Background}

Congestive heart failure (CHF) is a major cause of mortality and morbidity and the end pathophysiological condition of many cardiovascular diseases ${ }^{[1]}$. One of the leading causes of $\mathrm{CHF}$ is myocardial infarction. Percutaneous coronary intervention (PCI) significantly decreased the mortality in patients with acute myocardial infarction (AMI) ${ }^{[2]}$. However, CHF continues to develop in some patients before or soon after $\mathrm{PCl}$.

Exercise intolerance represented as decreased capacity to perform physical activities with symptoms of severe fatigue and/or dyspnea. It is a characteristic of CHF and associated with increased mortality and reduced quality of life $(\mathrm{Q} \circ \mathrm{L})^{[3]}$. The pathophysiological mechanisms of exercise intolerance in $\mathrm{CHF}$ are multifactorial, involving impaired cardiac and pulmonary reserve as well as decreased respiratory and peripheral skeletal muscle function ${ }^{[4]}$. In addition to conventional treatment, many researchers have 
shown that secondary prevention through comprehensive cardiac rehabilitation (CR) were the most costeffective intervention to ensure favourable outcomes, to improve exercise capacity and QoL, and to minimize re-hospitalizations in patients with $\mathrm{CHF}^{[5-7]}$. Furthermore, the use of web-based and mobile applications, telephonic interviews, and various wearable activity-tracking devices provides opportunities to regularly engage $\mathrm{CR}$ patients in secondary prevention at home, and has the potential to substantially increase accessibility, reduce costs, and improve prognosis ${ }^{[8]}$. However, studies on early CR in patients who developed CHF soon after AMI following PCl are scarce. A pilot study done by Houchen L et al. indicated that early CR could significantly reduce depression, enhance exercise tolerance and decrease CHF-associated hospital admission ${ }^{[9]}$.Unfortunately, the study population was small and no control group was presented for comparison. In view of this, this study evaluated patients with CHF after AMI following $\mathrm{PCl}$ with and without $\mathrm{CR}$, and compared biochemical parameters and cardio-respiratory fitness (CRF), as well as long-term prognosis at 4 years follow-up.

\section{Methods}

\section{Patient population:}

From January 2015 to January 2016, AMI patients with CHF following PCI were identified in the Department of Cardiology at the First Hospital of Jilin University, a large comprehensive tertiary hospital with over 2,000 beds. The study protocol was approved by the Institutional Review Board of the hospital.

Patients' baseline characteristics and biochemical parameters were collected from medical records. According to the 2016 ESC Guidelines for the diagnosis and treatment of acute and chronic heart failure [10], patients were divided into heart failure with reduced ejection fraction (HFrEF) group and heart failure with mid-range ejection fraction (HFmrEF) group. In each group, patients were further divided into $\mathrm{CR}$ and non-CR subgroups. CR consisted of 2 weeks of exercise including 3 supervised regular exercise sessions per week on a bicycle (Resistance System: Electromagnetically braked resistance, Power

Requirements: Self-generated, Watt: 250 Watts, Heart Rate Monitor: Wireless and Contact Grips) ${ }^{[11]}$ and 4 supervised electrical stimulation sessions per week for no regular exercise day ${ }^{[12]}$. Regular exercise session lasted for 20 minutes including warm-up and cool-down, and included three 3-minute intervals aiming at Borg 11-13 by subjective sensation separated by 2-minute recovery periods of 0 watt intensity ${ }^{[11]}$. Electrical stimulation was performed $30 \mathrm{~min} /$ day, 4 days per week, using a dual-channel batterypowered stimulator Elpha-II 3000 (DANMETER® A/S, Odense, Denmark). The stimulator delivered a biphasic current of $25 \mathrm{~Hz}$ frequency. The electrical current characteristics were set up as follows: "on-off" mode stimulus (3s stimulation, $6 \mathrm{~s}$ rest), pulse width $300 \mathrm{us}$, rise and fall time $1 \mathrm{~s}$. The intensity of the stimulation was adjusted to produce a visible muscle contraction but not too strong to make the patients uncomfortable ${ }^{[12]}$. Adhesive electrodes were placed on both legs over the upper and lower aspects of gastrocnemius muscles, and over the upper-lateral and lower-medial portions of the quadriceps muscles. After the 2 weeks CR, patients were advised to continue individualized exercise at home. Individualized exercise prescription was created based on each patient's CRF from cardio-pulmonary exercise testing 
(CPX) before discharge. The home exercise program included 3-4 sessions of walk or bicycle per week, in which the target training intensity was set at heart rate corresponding to ventilatory threshold (VT) ${ }^{[13]}$. Patients who accepted the 2-weeks CR were subsequently reassigned into two subgroups based on the major adverse cardiac events (MACE), namely the MACE group and the non-MACE group. The parameters of CPX between the two subgroups were compared, and the main CPX variables that may predict the prognosis of patients with CHF were identified.

\section{Quantification of cardio-respiratory fitness}

CPX was used for the assessment of CRF, which is a widely accepted evaluation tool in both the United States (US) and Europe ${ }^{[14,15]}$. The measurement of ventilatory gas exchange was used to predict prognosis of death and re-hospitalization ${ }^{[15-17]}$. In CR patients, the oxygen consumption $\left(\mathrm{VO}_{2}\right)$, carbon dioxide production $\left(\mathrm{VCO}_{2}\right)$, minute ventilation $(\mathrm{VE})$, partial pressure of end-tidal carbon dioxide $(\mathrm{PETCO})_{2}$, respiratory exchange ratio (RER) and other key CPX variables were measured with submaximal graded exercise test using cardio-respiratory instrumentation Medisoft (Made in Belgium, Model:E100000011000001N:130619-05-1470, ) after 2-week CR. The exercise load was determined by a cycle ergometer (egoselect 100 Typ: P mit BD, ergoline $\mathrm{GmbH}$ ) work rate. The progressive load was 10 watts per minute during the graded exercise test, and the pedaling cadence kept 55-65 revolutions per minute (RPM) throughout the test. The exercise test was terminated if the patient developed any of the following subjective or objective conditions: abnormal hemodynamic or ECG exercise response, or other causes such as dyspnea冈angina or lower extremity muscle fatigue.

\section{Clinical follow-up}

Follow-up data was acquired through hospital records and telephone interviews which were conducted every 3 months from discharge until cardiac death or July2019, whichever came first. MACE including cardiac death and re-hospitalization were documented. Patients with cardiac death who lost telephone interviews were identified from the population registry bureau. The average duration of follow-up was 4 years.

\section{Statistical analysis}

Continuous variables were expressed as means \pm standard deviation, and non-normally distributed variables were presented as medians (interquartile range). Categorical variables were expressed as numbers and percentages. Variable parameters between the groups were compared with means of oneway analysis of variance, or Mann-Whitney $U$ test for continuous variables and chi-square test for dichotomous variables, as appropriate. In all analyses, a two-tailed $\mathrm{P}<0.05$ was considered as statistical significance.

Corrections were made to account for the multiple comparisons by cox multivariate regression analysis, in which test indices and variables showing a p-value $<0.05$ in the univariate analysis were included, and were used to distinguish independent risk factors for MACE. A receiver operating characteristic (ROC) 
curve was used to predict the prognosis for MACE. All statistical analysis data were performed using the SPSS 19 software (IBM Corp., Armonk, NY, USA).

\section{Results}

A total of $274 \mathrm{AMI}$ patients with $\mathrm{CHF}$ following PCI were identified, 21 patients who were lost to follow-up and 16 patients (Multiple organ failure:2, Uremia:2, Ankylosing spondylitis:6, Diabetic ketosis:1, Diabetic foot:1, Systemic lupus erythematosus:1, Tumours:1, After aortic stent implantation:1, Left ventricular apical thrombus:1) who were not able to participate cardiopulmonary exercise testing (CPX) were excluded. 237 patients were included in the final analyses, 55 patients had $\operatorname{HFrEF}(n=22$ in CR and $n=33$ in non-CR group) and 182 had HFmrEF ( $n=56$ in CR and $n=126$ in non-CR group).

In HFrEF group, there were no significant differences in baseline characteristics between CR and non-CR groups except that the non-CR group patients were older (64.94 \pm 7.81 vs. $57.09 \pm 9.17, P=0.001)$ with fewer smokers (42.4\% vs. $72.7 \% \mathrm{P}=0.032$ ) (Table 1 ). In HFmrEF group, there were more male patients in non-CR group $(78.6 \%$ vs. $64.3 \%, \mathrm{P}=0.046)$ otherwise there were no significant differences in baseline characteristics between $\mathrm{CR}$ and non-CR groups (Table 2).

Incidence of major cardiovascular events

In the HFrEF group, non-CR patients had higher MACE rate $(60.6 \%$ vs. $18.2 \%, P=0.002)$ due to higher incidence of cardiac death (33.3\% vs. $0.00 \%, P=0.002$ ) as compared to $C R$ patients (Table 1, Figure 1 ). In the HFmrEF group, non-CR patients had higher MACE rate $(28.6 \%$ vs. $3.6 \%, P<0.001)$ due to higher incidence of heart failure (HF) re-hospitalization ( $14.3 \%$ vs. $1.8 \%, \mathrm{P}=0.008)$ as compared to CR patients (Table 2, Figure 2).

In HFrEF group, patients who developed MACE had higher serum potassium level $(4.40 \pm 0.54 \mathrm{mmol} / \mathrm{l} \mathrm{vs}$. $3.97 \pm 0.33 \mathrm{mmol} / \mathrm{l}, \mathrm{P}=0.001)$, lower end diastolic diameter of left ventricular (EDLV) $(54.00 \pm 5.96 \mathrm{~mm} \mathrm{vs}$. $57.84 \pm 5.67 \mathrm{~mm}, \mathrm{P}=0.018)$ and $\mathrm{CR}$ ratio $(16.7 \%$ vs. $58.1 \%, \mathrm{P}=0.002)$ compared to patients who did not have MACE (Table 3). Serum potassium ( $\mathrm{OR}=2.793 \varangle 95 \% \mathrm{Cl}: 1.207-6.465 \varangle \mathrm{P}=0.016)$ and $\mathrm{CR}$ ratio $(\mathrm{OR}=0.298 \otimes 95 \% \mathrm{Cl}: 0.099-0.902 \otimes \mathrm{P}=0.032)$ were independent risk factors for MACE of HFrEF patients, but not EDLV (OR=0.931ه95\% Cl: 0.866-1.001 $\otimes \mathrm{P}=0.054)$. In HFmrEF group, patients who developed MACE tended to be female $(P=0.013)$, older $(65.84 \pm 10.41$ vs. $57.69 \pm 11.64, P<0.001)$, with history of stroke (13.2\%, vs. $3.5 \%, P=0.035)$, with lower hemoglobin $(135.63 \pm 18.44 \mathrm{~g} / \mathrm{l}$ vs. $143.76 \pm 17.38 \mathrm{~g} / \mathrm{l}, \mathrm{P}=0.012)$, higher serum potassium ( $4.12 \mathrm{mmol} / \mathrm{l}$ vs. $3.98 \mathrm{mmol} / \mathrm{l}, \mathrm{P}=0.009)$, and lower the $\mathrm{CR}$ ratio ( $5.3 \% \mathrm{vs.} 37.5 \%$, $\mathrm{P}<0.001)$ (Table 4). Sex (OR=2.411ه95\% Cl: 1.150-5.054, $\mathrm{P}=0.020)$, age $(\mathrm{OR}=1.039 \otimes 95 \% \mathrm{Cl}: 1.008-1.071 \rrbracket$ $\mathrm{P}=0.014)$, history of stroke $(\mathrm{OR}=3.628 \otimes 95 \% \mathrm{Cl}: 1.288-10.219 \otimes \mathrm{P}=0.015)$, serum potassium $(\mathrm{OR}=3.054 \rrbracket$ $95 \% \mathrm{Cl}: 1.739-5.362 \otimes \mathrm{P}<0.001)$, and $\mathrm{CR}$ ratio $(\mathrm{OR}=0.115 \otimes 95 \% \mathrm{Cl}: 0.028-0.482 \otimes \mathrm{P}=0.003)$ were independent risk factors for MACE of HFmrEF patients, but not hemoglobin ( $\mathrm{OR}=0.987 \otimes 95 \% \mathrm{Cl}$ : 0.966-1.009ه $\mathrm{P}=0.240)$

The main CPX variables for prognosis prediction 
The 78 patients who accepted the 2-weeks CR were subsequently reassigned into two subgroups based on the MACEs, namely the MACE group $(n=6)$ and the non-MACE group $(n=72)($ Table 5$)$.

Compared with non-MACE group, more patients in MACE group were diabetic (66.7\% vs. $22.2 \%, P=0.035)$, had higher serum potassium $(4.31 \mathrm{mmol} / \mathrm{l}$ vs. $3.96 \mathrm{mmol} / \mathrm{l}, \mathrm{P}=0.043)$, higher incidence of heart failure rehospitalization $(P<0.001)$ and myocardial infarction $(P=0.005)$, and lower $P_{E T} C_{2}$ at VT $(P=0.016)$ (Table 5). $\mathrm{P}_{\mathrm{ET}} \mathrm{CO}_{2}$ at $\mathrm{VT}$ was found to have predictive value for re-hospitalization. The area under the curve was 0.789 and the cut-off point was $33.5 \mathrm{mmHg}$ (Figure 3). $\mathrm{P}_{\mathrm{ET}} \mathrm{CO}_{2}$ at VT was an independent risk factor for re-hospitalization ( $\mathrm{OR}=0.635,95 \% \mathrm{Cl}$ : $0.463-0.871, \mathrm{P}=0.005)$, but not serum potassium $(\mathrm{OR}=1.239,95 \% \mathrm{Cl}$ : $0.246-6.249, \mathrm{P}=0.795)$ and history of diabetes $(\mathrm{OR}=5.871,95 \% \mathrm{Cl}: 0.778-44.282, \mathrm{P}=0.086)$. The incidence of re-hospitalization was significantly lower when the $\mathrm{P}_{\mathrm{ET}} \mathrm{CO}_{2}$ at VT was higher than $33.5 \mathrm{mmHg}(0(0.00 \%$ vs. $6(13.64 \%), P=0.03$ ) (Figure 4).

\section{Discussion}

The present study is the first retrospective study evaluating early CR in patients with heart failure after $\mathrm{AMI}$ following $\mathrm{PCl}$. The main findings of this study suggest that early $\mathrm{CR}$ was able to reduce cardiogenic death in patients with HFrEF, and reduce re-hospitalization in patients with HFmrEF after AMI. Furthermore, the intervention was safe; $\mathrm{P}_{\mathrm{ET}} \mathrm{CO}_{2}$ at VT was an independent risk factor for rehospitalization.

In patients with HF, research suggested that exercise-based CR could improve QoL, decrease all-cause hospital admissions and HF-dependent hospital admissions in the short term (up to 12 months) and potentially reduce mortality in the long term when compared to no exercise patients ${ }^{[18,19]}$. Our study expands the previous research by showing that early rehabilitation program involving supervised regular exercise and electrical stimulation can reduce the incidence of cardiac death in patients with HFrEF, and heart failure re-hospitalization in patients with HFmrEF. Elevated serum potassium level and CR ratio were independent risk factors for cardiac death in HFrEF patients after AMI. Moreover, our study suggests that sex, age $\bigotimes$ history of stroke, and elevated serum potassium were independent risk factors for rehospitalization in patients with HFmrEF after AMI. Thomsen et.al also reported that hyperkalemia was strongly associated with the degree of renal dysfunction and severe clinical outcomes as well as death in HF patients ${ }^{[20]}$. Though two-week intervention in the CR-group seems quite short to make such a big effect on the outcome, possible reasons are: First, although the two-week early rehabilitation has little effect on cardiac function, the enhancement of lower limb muscle endurance could have improved the exercise intolerance of these patients, and it could make the patients interested in exercise rehabilitation and enhance their confidence in improving the QoL. Second, before discharge, individualized exercise prescription was made for CR patients according to VT level by CPX, so each patient knew how much exercise intensity and how long exercise time was safe and effective at home. Through tailored exercise experience, they could feel at ease rather than fear for exercise. As a result, they could continue their exercise after discharge. Third, every three months at follow-up, the CR patients would be reminded to 
exercise according to the individualized exercise prescription. However, the non-CR patients were only reminded to exercise moderately. Taken together, the greater role of early rehabilitation is to provide physical fitness reserve and mental self-confidence for the continuous implementation of long-term exercise rehabilitation at home. Typically, an outpatient CR for secondary prevention includes 3-4 weekly supervised exercise and educational sessions for 12 weeks. Despite the health benefits associated with these interventions, few cardiovascular patients could complete such programs. Similar to our study, recent research found that early hospital practice guidance, tailored physical activity intervention and follow-up $(1,2,3$, and 4 months after hospital discharge) at home can effectively improve physical performance, QoL, and frailty status in elderly acute coronary syndrome patients ${ }^{[21,22]}$. Taken together, an important role is played by early CR that helps patients to make home-based tailored exercise a habit and maintain their improvement. This can help to overcome the main limitations of typical outpatient CR, such as the high number of sessions, high costs, low compliance and lack of long-term maintenance of an active lifestyle.

Exercise intolerance is a major feature of $\mathrm{CHF}$, and is associated with impaired QoL, reduced functional capacity and poor prognosis. In addition to reduced cardiac function, other causes such as reduced pulmonary reserve, impaired skeletal muscle function, etc can diversely and significantly contribute to the syndrome in CHF patients, and even turn into the dominant mechanisms of exercise intolerance ${ }^{[23]}$. Exercise can provide numerous benefits for $\mathrm{CHF}$ patients including decreased long-term morbidity and mortality [24], improved cardiac remodeling ${ }^{[25]}$, increased neurovascular functional competency [26], reduced re-hospitalization and improved of cardiorespiratory capacity and QoL ${ }^{[1,27]}$. The benefits of electrical stimulation included improving blood supply and muscle strength, as well as exercise tolerance in severe CHF patients ${ }^{[28,29]}$, so it could be offered as an alternative to bicycle training as part of a homebased rehabilitation program ${ }^{[12]}$. In our study, the re-hospitalization in patients who accepted the 2-week $\mathrm{CR}$ after $\mathrm{PCl}$ was only related to CRF, but not to serum potassium level or history of diabetes. The reason may be related to the protective effects of exercise on renal function and the improvement of glycolipid metabolism. Our previous research suggested that upregulation of nitric oxide synthases in the kidney and left ventricle may contribute, in part, to the renal and cardiac protective effects of exercise training in cardiorenal syndrome in chronic heart failure rats ${ }^{[30]}$. Furthermore, exercise can reduce early diabetic nephropathy by upregulating nitric oxide synthases as well as ameliorating NADPH oxidase and aoxoaldehydes in the kidneys of zucker diabetic fatty (ZDF) rats ${ }^{[31]}$.

CRF is now being considered as an essential variable and should be assessed in health screenings ${ }^{\text {[32] }}$. The clinical values of CRF assessment include diagnosis, functional evaluation and prognosis prediction. $\mathrm{CPX}$ is the most precise tool to determine exercise tolerance and considered as the reference clinical procedure for assessing CRF by quantifying peak $\mathrm{VO}_{2}$ which represents an individuals' capacity to generate energy for strenuous exercise ${ }^{[32]}$. $\mathrm{CHF}$ is a systemic syndrome with the reduction of functional reserve being the outstanding characteristic. The cardiovascular impairment has a direct negative effect on other systems and organs, including the respiratory, renal and neuromuscular systems. CPX is defined as "gold standard" for the CRF of patients with cardiovascular disease, the clinical diagnosis assessment 
and prognosis prediction can be achieved from direct measurement of $\mathrm{VO}_{2}, \mathrm{VCO}_{2}$ and $\mathrm{VE}{ }^{[33]}$. The characteristic of CPX data in patients with CHF are: decreased $\mathrm{VO}_{2}$ at $\mathrm{VT}<40 \%$ of the predicted $\mathrm{VO}_{2} \max$, $\mathrm{O}_{2}$ pulse $<85 \%$ of the age-predicted value and as a plateau, increased $\mathrm{VE} / \mathrm{VCO}_{2}$, wide breathing reserve and usually normal $\mathrm{O}_{2}$ saturation ${ }^{[33,34]}$. The 2012 EACPR/AHA scientific statement endorsed that peak $\mathrm{VO}_{2}$ and $\mathrm{VE} / \mathrm{VCO}_{2}$ slope are the most studied CRF variables in $\mathrm{CHF}$ patients and both indicated significantly independent prognostic value ${ }^{[13]}$. For patients under medical treatment, a peak $\mathrm{VO}_{2}<10.0$ $\mathrm{ml} / \mathrm{kg} / \mathrm{min}$ and a $\mathrm{VE} / \mathrm{VCO}_{2}$ slope $\geqq 45$ exist at the same time would indicate a very poor prognosis over the following 4 -year ${ }^{[13]}$.Similarly our results indicated that $\mathrm{CR}$ patients with $\mathrm{VE} / \mathrm{VCO}_{2}$ slope $<36$ had a good cardiovascular prognosis. Others evaluating the long term prognosis by $\mathrm{VE} / \mathrm{VCO} 2$ slope in $\mathrm{CHF}$, and reported that it was an excellent independent value, even better than peak $\mathrm{VO}_{2}$, and could be achieved only from sub-maximal exercise ${ }^{[35,36]}$.

It should be noted that, in order to achieve the prediction accuracy of peak $\mathrm{VO}_{2}$ value on $\mathrm{CHF}$, maximal exercise (at least RER>1.05) should be achieved during the test ${ }^{[33]}$. However, it is difficult to achieve a maximal test in most CHF patients due to the exercise intolerance. The 2016 EACPR/AHA updated the scientific statement, and felt that it is important to note that $\mathrm{VO}_{2}$ at VT holds broad applicability in the context of assessing the capacity ${ }^{[37]}$. The $\mathrm{VO}_{2}$ at $\mathrm{VT}$ has also been indicated as a hallmark for the prognosis prediction prior to surgery ${ }^{[38,39]}$. Furthermore, we also showed that $\mathrm{VO}_{2}$ at $\mathrm{VT}$ is a significant prognostic marker for AMI patients in whom a $\mathrm{VO}_{2}$ at $\mathrm{VT}<10.5 \mathrm{ml} / \mathrm{kg} / \mathrm{min}$ indicated a poor long term prognosis ${ }^{[40]}$. The $\mathrm{P}_{\mathrm{ET}} \mathrm{CO}_{2}$ both at rest and in exercise have been found to be positively correlated with the prognosis of systolic heart failure ${ }^{[41]}$. Abnormalities in the $\mathrm{P}_{\mathrm{ET}} \mathrm{CO}_{2}$ in patients with $\mathrm{HCM}$ have been

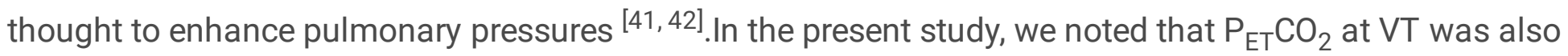
a predictor of re-hospitalization for patients with CHF after AMI.

Our previous study demonstrated that $\mathrm{VO}_{2}$ at VT was an independent risk factor for cardiovascular disease prognosis and could be used as an evaluating hallmark for Phase I cardiac rehabilitation in patients with acute ST segment elevation myocardial infarction (STEMI) after PCI ${ }^{[40]}$. However, the $\mathrm{P}_{\mathrm{ET}} \mathrm{CO}_{2}$ at $\mathrm{VT}$ is an independent risk factor for re-hospitalization in patients with heart failure after $\mathrm{AMI}$. The reasons of the difference may be as follows: first, patients with STEMI after PCI may not have reduced ejection fraction and severe pulmonary dysfunction after $\mathrm{PCl}$ operation, a smaller amount of $\mathrm{P}_{\mathrm{ET}} \mathrm{CO}_{2}$ is an indicator of less $\mathrm{CO}_{2}$ production in the body and/or pulmonary arterial perfusion, or in other words, the cardiac output ${ }^{[43]}$. The difference in $\mathrm{P}_{\mathrm{ET}} \mathrm{CO}_{2}$ might be attributed to the difference in infarct location. $\mathrm{VO}_{2}$ at $\mathrm{VT}$ is determined not only by the degree of the infarct area but also the peripheral oxygen utilization efficiency, and could be an independent risk factor for the prognosis in patients with STEMI after $\mathrm{PCl}$. Second, ventilation is regulated by the sensitivity of respiratory chemo-receptors and the ergo reflex in skeletal muscles. The sensitivity of respiratory chemo-receptors increases when the sympathetic nerve is activated and/or acidosis occurs. These conditions often occur in HF patients ${ }^{[44]}$. These subjects 
experience shortness of breath throughout mild to vigorous activity. While in insufficiently expansion and with increased dead space between artery and alveolus, diffusion of $\mathrm{CO}_{2}$ is less, hence, $\mathrm{PET}_{\mathrm{ET}} \mathrm{CO}_{2}$ decreases. The re-hospitalization associated with exercise intolerance in patients with $\mathrm{CHF}$ are multifactorial, including impaired cardiac and pulmonary reserve, and decreased respiratory and peripheral skeletal muscle function, all of them can diversely and significantly contribute to the decrease in $\mathrm{P}_{\mathrm{ET}} \mathrm{CO}_{2}$. The combined aerobic/resistance/inspiratory training in patients with $\mathrm{CHF}$ has been shown to produce positive changes in left ventricular structure and function, which provided additional benefits in both peripheral and diaphragmatic muscle function, dyspnea, cardiopulmonary exercise parameters and QoL ${ }^{[45]}$.

The limitations of this study include: (1) The patients in the non-CR group were not assessed for CRF using CPX before discharge. So, it is not clear which parameters of cardiopulmonary fitness (cardiac outcome or pulmonary reserve or peripheral skeletal muscle function) can be improved by early rehabilitation in two weeks. (2) The number of re-hospitalized patients who participated in early CR was low. Therefore, the influence of CRF parameters on prognosis prediction and the accuracy of cut-off value needs further research. (3) Lack of home exercise data in CR group and non-CR group, so further research is needed to explore the influence of early CR on home-based healthy lifestyle development and the influence of home exercise amount on long-term prognosis.

In conclusion, an early CR decreased the incidence of cardiovascular events in patients with CHF after AMI following PCl. Elevated serum potassium and $\mathrm{CR}$ ratio were independent risk factors for MACE in patients not only with HFrEF but also with HFmrEF after AMI. The $\mathrm{P}_{E T} \mathrm{CO}_{2}$ at VT was an independent risk factor for re-hospitalization, and could be used as a key evaluating hallmark for early CR in patients with CHF after AMI.

\section{List Of Abbreviations}

AMI: acute myocardial infarction

CHF: congestive heart failure

CR: cardiac rehabilitation

PCl: percutaneous coronary intervention

HFrEF: heart failure with reduced ejection fraction

HFmrEF: heart failure with mid-range ejection fraction

STEMI\acute ST segment elevation myocardial infarction

ZDF囚zucker diabetic fatty 
MACE: major adverse cardiovascular events

CPX: cardio-pulmonary exercise testing

CRF: cardio-respiratory fitness

QoL: quality of life

$\mathrm{VO}_{2}$ : oxygen consumption

$\mathrm{VCO}_{2}$ : carbon dioxide production

VE: minute ventilation

$\mathrm{P}_{\mathrm{ET}} \mathrm{CO}_{2}$ : partial pressure of end-tidal carbon dioxide

RER: respiratory exchange ratio

ROC: receiver operating characteristic

WBC: white blood cell

Cr: creatinine

AST: glutamic pyruvic ransaminase

ALT: glutamic pyruvic aminotransferase

TC: total cholesterol

HDL-C: high-density lipoprotein cholesterol

non-HDL-C: non high-density lipoprotein cholesterol

FBG: fasting blood glucose

HGB: hemoglobin

EDLV: End diastolic diameter of left ventricle

EF: Ejection fraction

\section{Declarations}

Ethics approval and consent to participate 
This work was approved by Medical Ethics Committee of The First Hospital of Jilin University (approval Number: 2016-281) and was exempted from the requirement for informed consent. All information used for data analysis in this study was anonymized.

\section{Consent for publication}

Not applicable.

\section{Availability of data and materials}

The data used to support the findings of this study are available from the corresponding author upon request.

\section{Competing interests}

The authors declare that they have no competing interests, and all authors should confirm its accuracy.

\section{Funding}

This assessment is funded by National Key R\&D Program of China区NO. 2016YFC0900903, and National Natural Science Foundation of China: N0.81301667(3A413X793428). The funding bodies were not involved in the study design, data collection or analysis, or writing of the manuscript.

\section{Authors' contributions}

P.C. and Y.Z. conceived and designed the study. H.C., Z.L., X.Z., R.L., W.S., L.W. and L.Z. performed the experiments and statistical analysis. H.C. wrote the paper. P.C. and Y.Z. reviewed and edited the manuscript. All authors read and approved the manuscript.

\section{Acknowledgements}

We thank all the researchers who participated in this work and the funding bodies that sponsored this study.

\section{References}

[1] Yancy CW, Jessup M, Bozkurt B, et al. 2013 ACCF/AHA guideline for the management of heart failure: a report of the American College of Cardiology Foundation/American Heart Association Task Force on Practice Guidelines. J Am Coll Cardiol. 2013. 62(16): e147-239.

[2] Smith SC Jr, Dove JT, Jacobs AK, et al. ACC/AHA guidelines of percutaneous coronary interventions (revision of the 1993 PTCA guidelines)--executive summary. A report of the American College of Cardiology/American Heart Association Task Force on Practice Guidelines (committee to revise the 1993 guidelines for percutaneous transluminal coronary angioplasty). J Am Coll Cardiol. 2001. 37(8): 2215-39. 
[3] Piña IL, Apstein CS, Balady GJ, et al. Exercise and heart failure: A statement from the American Heart Association Committee on exercise, rehabilitation, and prevention. Circulation. 2003. 107(8): 1210-25.

[4] Haykowsky MJ, Tomczak CR, Scott JM, Paterson DI, Kitzman DW. Determinants of exercise intolerance in patients with heart failure and reduced or preserved ejection fraction. J Appl Physiol (1985). 2015. 119(6): 739-44.

[5] Rees K, Taylor RS, Singh S, Coats AJ, Ebrahim S. Exercise based rehabilitation for heart failure. Cochrane Database Syst Rev. 2004. (3): CD003331.

[6] Piepoli MF, Davos C, Francis DP, Coats AJ, ExTraMATCH Collaborative. Exercise training meta-analysis of trials in patients with chronic heart failure (ExTraMATCH). BMJ. 2004. 328(7433): 189.

[7] Ambrosetti M, Abreu A, Corrà U, et al. Secondary prevention through comprehensive cardiovascular rehabilitation: From knowledge to implementation. 2020 update. A position paper from the Secondary Prevention and Rehabilitation Section of the European Association of Preventive Cardiology. Eur J Prev Cardiol. 2020 : 2047487320913379.

[8] Lavie CJ, Arena R, Franklin BA. Cardiac Rehabilitation and Healthy Life-Style Interventions: Rectifying Program Deficiencies to Improve Patient Outcomes. J Am Coll Cardiol. 2016. 67(1): 13-5.

[9] Houchen L, Watt A, Boyce S, Singh S. A pilot study to explore the effectiveness of "early" rehabilitation after a hospital admission for chronic heart failure. Physiother Theory Pract. 2012. 28(5): 355-8.

[10] Ponikowski P, Voors AA, Anker SD, et al. [2016 ESC Guidelines for the diagnosis and treatment of acute and chronic heart failure]. Kardiol Pol. 2016. 74(10): 1037-1147.

[11] Støylen A, Conraads V, Halle M, Linke A, Prescott E, Ellingsen $\emptyset$. Controlled study of myocardial recovery after interval training in heart failure: SMARTEX-HF--rationale and design. Eur J Prev Cardiol. 2012. 19(4): 813-21.

[12] Harris S, LeMaitre JP, Mackenzie G, Fox KA, Denvir MA. A randomised study of home-based electrical stimulation of the legs and conventional bicycle exercise training for patients with chronic heart failure. Eur Heart J. 2003. 24(9): 871-8.

[13] Guazzi M, Adams V, Conraads V, et al. EACPR/AHA Scientific Statement. Clinical recommendations for cardiopulmonary exercise testing data assessment in specific patient populations. Circulation. 2012. 126(18): 2261-74.

[14] Arena R, Myers J, Guazzi M. The future of aerobic exercise testing in clinical practice: is it the ultimate vital sign. Future Cardiol. 2010. 6(3): 325-42.

[15] Lauer M, Froelicher ES, Williams M, Kligfield P, American Heart Association Council on Clinical Cardiology, Subcommittee on Exercise, Cardiac Rehabilitation aP. Exercise testing in asymptomatic 
adults: a statement for professionals from the American Heart Association Council on Clinical Cardiology, Subcommittee on Exercise, Cardiac Rehabilitation, and Prevention. Circulation. 2005. 112(5): 771-6.

[16] Balady GJ, Arena R, Sietsema K, et al. Clinician's Guide to cardiopulmonary exercise testing in adults: a scientific statement from the American Heart Association. Circulation. 2010. 122(2): 191-225.

[17] Kaminsky LA, Arena R, Myers J. Reference Standards for Cardiorespiratory Fitness Measured With Cardiopulmonary Exercise Testing: Data From the Fitness Registry and the Importance of Exercise National Database. Mayo Clin Proc. 2015. 90(11): 1515-23.

[18] Taylor RS, Sagar VA, Davies EJ, et al. Exercise-based rehabilitation for heart failure. Cochrane Database Syst Rev. 2014. (4): CD003331.

[19] Long L, Mordi IR, Bridges C, et al. Exercise-based cardiac rehabilitation for adults with heart failure. Cochrane Database Syst Rev. 2019. 1: CD003331.

[20] Thomsen RW, Nicolaisen SK, Hasvold P, et al. Elevated Potassium Levels in Patients With Congestive Heart Failure: Occurrence, Risk Factors, and Clinical Outcomes: A Danish Population-Based Cohort Study. J Am Heart Assoc. 2018. 7(11).

[21] Tonet E, Maietti E, Chiaranda G, et al. Physical activity intervention for elderly patients with reduced physical performance after acute coronary syndrome (HULK study): rationale and design of a randomized clinical trial. BMC Cardiovasc Disord. 2018. 18(1): 98.

[22] Campo G, Tonet E, Chiaranda G, et al. Exercise Intervention to Improve Functional Capacity in Older Adults After Acute Coronary Syndrome. J Am Coll Cardiol. 2019. 74(23): 2948-2950.

[23] Del Buono MG, Arena R, Borlaug BA, et al. Exercise Intolerance in Patients With Heart Failure: JACC State-of-the-Art Review. J Am Coll Cardiol. 2019. 73(17): 2209-2225.

[24] Smart N, Marwick TH. Exercise training for patients with heart failure: a systematic review of factors that improve mortality and morbidity. Am J Med. 2004. 116(10): 693-706.

[25] Haykowsky MJ, Liang Y, Pechter D, Jones LW, McAlister FA, Clark AM. A meta-analysis of the effect of exercise training on left ventricular remodeling in heart failure patients: the benefit depends on the type of training performed. J Am Coll Cardiol. 2007. 49(24): 2329-36.

[26] Antunes-Correa LM, Kanamura BY, Melo RC, et al. Exercise training improves neurovascular control and functional capacity in heart failure patients regardless of age. Eur J Prev Cardiol. 2012. 19(4): 822-9.

[27] Davies EJ, Moxham T, Rees K, et al. Exercise training for systolic heart failure: Cochrane systematic review and meta-analysis. Eur J Heart Fail. 2010. 12(7): 706-15. 
[28] Dobsák P, Nováková M, Siegelová J, et al. Low-frequency electrical stimulation increases muscle strength and improves blood supply in patients with chronic heart failure. Circ J. 2006. 70(1): 75-82.

[29] Karavidas A, Parissis JT, Matzaraki V, et al. Functional electrical stimulation is more effective in severe symptomatic heart failure patients and improves their adherence to rehabilitation programs. $J$ Card Fail. 2010. 16(3): 244-9.

[30] Ito D, Ito O, Mori N, et al. Exercise training upregulates nitric oxide synthases in the kidney of rats with chronic heart failure. Clin Exp Pharmacol Physiol. 2013. 40(9): 617-25.

[31] Ito D, Cao P, Kakihana T, et al. Chronic Running Exercise Alleviates Early Progression of Nephropathy with Upregulation of Nitric Oxide Synthases and Suppression of Glycation in Zucker Diabetic Rats. PLoS One. 2015. 10(9): e0138037.

[32] Kaminsky LA, Arena R, Ellingsen $\varnothing$, et al. Cardiorespiratory fitness and cardiovascular disease - The past, present, and future. Prog Cardiovasc Dis. 2019. 62(2): 86-93.

[33] Herdy AH, Ritt LE, Stein R, et al. Cardiopulmonary Exercise Test: Background, Applicability and Interpretation. Arq Bras Cardiol. 2016. 107(5): 467-481.

[34] Herdy AH, Uhlendorf D. Reference values for cardiopulmonary exercise testing for sedentary and active men and women. Arq Bras Cardiol. 2011. 96(1): 54-9.

[35] Francis DP, Shamim W, Davies LC, et al. Cardiopulmonary exercise testing for prognosis in chronic heart failure: continuous and independent prognostic value from VE/VCO(2)slope and peak VO(2). Eur Heart J. 2000. 21(2): 154-61.

[36] Corrà U, Mezzani A, Bosimini E, Scapellato F, Imparato A, Giannuzzi P. Ventilatory response to exercise improves risk stratification in patients with chronic heart failure and intermediate functional capacity. Am Heart J. 2002. 143(3): 418-26.

[37] Guazzi M, Arena R, Halle M, Piepoli MF, Myers J, Lavie CJ. 2016 Focused Update: Clinical Recommendations for Cardiopulmonary Exercise Testing Data Assessment in Specific Patient Populations. Circulation. 2016. 133(24): e694-711.

[38] Hennis PJ, Meale PM, Grocott MP. Cardiopulmonary exercise testing for the evaluation of perioperative risk in non-cardiopulmonary surgery. Postgrad Med J. 2011. 87(1030): 550-7.

[39] Smith TB, Stonell C, Purkayastha S, Paraskevas P. Cardiopulmonary exercise testing as a risk assessment method in non cardio-pulmonary surgery: a systematic review. Anaesthesia. 2009. 64(8): 883-93.

[40] Cai H, Zheng Y, Liu Z, et al. Effect of pre-discharge cardiopulmonary fitness on outcomes in patients with ST-elevation myocardial infarction after percutaneous coronary intervention. BMC CardiovasC 
Disord. 2019. 19(1): 210.

[41] Task Force of the Italian Working Group on Cardiac Rehabilitation Prevention, Working Group on Cardiac Rehabilitation and Exercise Physiology of the European Society of Cardiology, Piepoli MF, et al. Statement on cardiopulmonary exercise testing in chronic heart failure due to left ventricular dysfunction: recommendations for performance and interpretation. Part l: definition of cardiopulmonary exercise testing parameters for appropriate use in chronic heart failure. Eur J Cardiovasc Prev Rehabil. 2006. 13(2): 150-64.

[42] Weber KT, Kinasewitz GT, Janicki JS, Fishman AP. Oxygen utilization and ventilation during exercise in patients with chronic cardiac failure. Circulation. 1982. 65(6): 1213-23.

[43] Arena R, Myers J, Abella J, et al. Defining the optimal prognostic window for cardiopulmonary exercise testing in patients with heart failure. Circ Heart Fail. 2010. 3(3): 405-11.

[44] Adachi H. Cardiopulmonary Exercise Test. Int Heart J. 2017. 58(5): 654-665.

[45] Laoutaris ID, Adamopoulos S, Manginas A, et al. Benefits of combined aerobic/resistance/inspiratory training in patients with chronic heart failure. A complete exercise model? A prospective randomised study. Int J Cardiol. 2013. 167(5): 1967-72.

\section{Tables}

Table 1. Baseline characteristics and MACE (4 years) of CR patients and NCR patients with HFrEF 


\begin{tabular}{|c|c|c|c|}
\hline & \multicolumn{3}{|c|}{ HFrEF group $[n=55 \square$} \\
\hline & $\begin{array}{c}\text { CR } \\
\square n=22 \square\end{array}$ & $\begin{array}{c}\text { NCR } \\
\square n=33 \square\end{array}$ & $P$ \\
\hline Sex, male (\%) & $17(77.3 \%)$ & $26(78.8 \%)$ & 1.000 \\
\hline Age (years) & $57.09 \pm 9.17$ & $64.94 \pm 7.81$ & 0.001 \\
\hline History of hypertension, $\mathrm{n}(\%)$ & $13(59.1 \%)$ & $15(45.5 \%)$ & 0.412 \\
\hline History of diabetes, $n(\%)$ & $6(27.3 \%)$ & $12(36.4 \%)$ & 0.565 \\
\hline Smoking history, $n(\%)$ & $16(72.7 \%)$ & $14(42.4 \%)$ & 0.032 \\
\hline History of stroke, $n(\%)$ & $2(9.1 \%)$ & $2(6.1 \%)$ & 1.000 \\
\hline WBC $\left(10^{9} / \mathrm{L}\right)$, median (IQR) & $9.13 \pm 3.22$ & $10.36 \pm 3.73$ & 0.212 \\
\hline Platelet $\left(10^{9} / \mathrm{L}\right)$, median (IQR) & $217.45 \pm 67.00$ & $197.42 \pm 75.13$ & 0.317 \\
\hline HGB (g/l) & $139 \pm 22.31$ & $133.39 \pm 20.31$ & 0.339 \\
\hline Blood potassium (mmol/l) & $4.06 \pm 0.40$ & $4.22 \pm 0.53$ & 0.229 \\
\hline Urea nitrogen $(\mathrm{mmol} / \mathrm{l})$, median (IQR) & $6.19 \pm 1.57$ & $5.76 \pm 2.30$ & 0.451 \\
\hline Creatinine (umol/L), median (IQR) & $\begin{array}{c}76.70 \\
(64.25,92.85)\end{array}$ & $\begin{array}{c}80.00 \\
(63.65,95.35)\end{array}$ & 0.904 \\
\hline AST (U/L), median (IQR) & $\begin{array}{c}108.3 \\
(22.05,353.72)\end{array}$ & $\begin{array}{c}120.4 \\
(27.75,420.25)\end{array}$ & 0.327 \\
\hline ALT (U/L), median (IQR) & $\begin{array}{c}44.05 \\
(25.33,76.45)\end{array}$ & $\begin{array}{c}51.4 \\
(20.7,93.8)\end{array}$ & 0.624 \\
\hline HDL-C (mmol/l) & $1.09 \pm 0.23$ & $1.16 \pm 0.33$ & 0.380 \\
\hline non-HDL-C (mmol/l) & $3.58 \pm 0.95$ & $3.46 \pm 1.28$ & 0.707 \\
\hline TC (mmol/L), median (IQR) & $1.46(1.07,2.03)$ & $1.31(0.93,2.18)$ & 0.525 \\
\hline FBS (mmol/L), median (IQR) & $\begin{array}{c}6.14 \\
(5.51,7.39)\end{array}$ & $\begin{array}{c}7.08 \\
(5.84,11.04)\end{array}$ & 0.071 \\
\hline EDLV(mm) & $58.09 \pm 5.52$ & $54.88 \pm 6.13$ & 0.053 \\
\hline $\mathrm{EF}(\%)$, median (IQR) & $34(31,37)$ & $35(30,38)$ & 0.938 \\
\hline Target lesion location & & & \\
\hline LAD, n (\%) & $10(45.5 \%)$ & $17(51.5 \%)$ & 0.790 \\
\hline LCX, n (\%) & $2(9.1 \%)$ & $3(9.1 \%)$ & 1.000 \\
\hline RCA, $n(\%)$ & $10(45.5 \%)$ & $13(39.4 \%)$ & 0.782 \\
\hline KILLIP class & & & \\
\hline
\end{tabular}

Page 16/27 


\begin{tabular}{|l|c|c|c|} 
I, n (\%) & $0(0.0 \%)$ & $0(0.0 \%)$ & - \\
II, n (\%) & $7(31.8 \%)$ & $12(36.4 \%)$ & 0.780 \\
III, n (\%) & $12(54.5 \%)$ & $10(30.3 \%)$ & 0.100 \\
IV, n (\%) & $3(13.6 \%)$ & $11(33.3 \%)$ & 0.130 \\
\hline Cardiogenic death, n (\%) & $0(0.0 \%)$ & $11(33.3 \%)$ & 0.002 \\
\hline Rehospitalization, n (\%) & $4(18.2 \%)$ & $9(27.3 \%)$ & 0.528 \\
Myocardial infarction, n(\%) & $1(4.5 \%)$ & $6(18.2 \%)$ & 0.223 \\
Heart failure, n (\%) & $3(13.6 \%)$ & $3(9.1 \%)$ & 0.674 \\
Stroke, n(\%) & $0(0.0 \%)$ & $0(0.0 \%)$ & - \\
& & & 0.002 \\
\hline MACE, n (\%) & $4(18.2 \%)$ & $20(60.6 \%)$ & \\
\hline
\end{tabular}

HFrEF: Heart failure with reduced ejection fraction, HFmrEF: Heart failure with mid-range ejection fraction, CR: Cardiac rehabilitation, NCR: Non cardiac rehabilitation, WBC: White blood cell, HGB: Hemoglobin, AST: Glutamic pyruvic transaminase, ALT: Glutamic pyruvic aminotransferase, HDL-C: High density lipoprotein cholesterol, non- HDL-C: non-High density lipoprotein cholesterol, TC: total cholesterol, FBS: Fasting blood sugar, EDLV: End diastolic diameter of left ventricle, EF: Ejection fraction, LM: The left main coronary artery, LAD: Left anterior descending branch, LCX: Left circumflex branch, RCA: Right coronary artery, MACE: major cardiac events, IQR: Interquartile range.

Table 2. Baseline characteristics and MACE (4 years) of CR patients and NCR patients with HFmrEF. 


\begin{tabular}{|c|c|c|c|}
\hline & \multicolumn{3}{|c|}{ HFmrEF group $\llbracket n=182 \square$} \\
\hline & $\begin{array}{c}\text { CR } \\
\square n=56 \square\end{array}$ & $\begin{array}{c}\text { NCR } \\
\square n=126 \square\end{array}$ & $P$ \\
\hline Sex, male (\%) & $36(64.3 \%)$ & $99(78.6 \%)$ & 0.046 \\
\hline Age (years) & $58.84 \pm 10.37$ & $59.63 \pm 12.47$ & 0.677 \\
\hline History of hypertension, $\mathrm{n}(\%)$ & $29(51.8 \%)$ & $60(47.6 \%)$ & 0.633 \\
\hline History of diabetes, $\mathrm{n}(\%)$ & $14(25 \%)$ & $36(28.6 \%)$ & 0.720 \\
\hline Smoking history, n(\%) & $28(50 \%)$ & $79(62.7 \%)$ & 0.142 \\
\hline History of stroke, n (\%) & $1(1.8 \%)$ & $9(7.1 \%)$ & 0.285 \\
\hline WBC $\left(10^{9} / \mathrm{L}\right)$, median (IQR) & $\begin{array}{c}9.88 \\
(7.70,12.89)\end{array}$ & $\begin{array}{c}9.84 \\
(7.83,12.44)\end{array}$ & 0.913 \\
\hline Platelet $\left(10^{9} / \mathrm{L}\right)$, median (IQR) & $\begin{array}{c}228.5 \\
(186,271.75)\end{array}$ & $\begin{array}{c}216.5 \\
(180.5,245.25)\end{array}$ & 0.128 \\
\hline HGB (g/l) & $141.68 \pm 17.316$ & $142.24 \pm 18.165$ & 0.846 \\
\hline Blood potassium (mmol/l) & $3.92(3.66,4.14)$ & $4.03(3.77,4.28)$ & 0.123 \\
\hline Urea nitrogen (mmol/l) , median (IQR) & $5.27(4.20,6.27)$ & $5.57(4.80,6.91)$ & 0.136 \\
\hline Creatinine (umol/L), median (IQR) & $\begin{array}{c}63.80 \\
(56.53,82.80)\end{array}$ & $\begin{array}{c}70.65 \\
(57.50,81.55)\end{array}$ & 0.541 \\
\hline AST (U/L), median (IQR) & $\begin{array}{c}71.65 \\
(34.43,198.98)\end{array}$ & $\begin{array}{c}94.60 \\
(41.73,224.08)\end{array}$ & 0.151 \\
\hline ALT (U/L), median (IQR) & $\begin{array}{c}45.15 \\
(24.20,67.63)\end{array}$ & $\begin{array}{c}44.70 \\
(28.68,69.00)\end{array}$ & 0.536 \\
\hline $\mathrm{HDL}-\mathrm{C}(\mathrm{mmol} / \mathrm{l})$ & $1.19(1.00,1.38)$ & $1.21(1.00,1.52)$ & 0.306 \\
\hline non-HDL-C (mmol/l) & $3.60 \pm 0.93$ & $3.48 \pm 1.07$ & 0.467 \\
\hline TC (mmol/L), median (IQR) & $1.33(1.00,2.02)$ & $1.40(1.02,2.07)$ & 0.832 \\
\hline FBS (mmol/L), median (IQR) & $6.60(4.93,8.37)$ & $6.59(5.37,9.50)$ & 0.350 \\
\hline $\mathrm{EDLV}(\mathrm{mm})$ & $52.04 \pm 5.30$ & $51.19 \pm 5.02$ & 0.304 \\
\hline $\mathrm{EF}(\%)$, median (IQR) & $46(42,48)$ & $46(44,49)$ & 0.050 \\
\hline \multicolumn{4}{|l|}{ Target lesion location } \\
\hline $\mathrm{LAD}, \mathrm{n}(\%)$ & $41(73.2 \%)$ & $88(69.8 \%)$ & 0.730 \\
\hline LCX, n (\%) & $2(3.6 \%)$ & $6(4.8 \%)$ & 1.000 \\
\hline RCA, n (\%) & $13(23.2 \%)$ & $32(25.4 \%)$ & 0.853 \\
\hline KILLIP class & & & \\
\hline
\end{tabular}

Page 18/27 


\begin{tabular}{|l|c|c|c|} 
I, n (\%) & $0(0.0 \%)$ & $0(0.0 \%)$ & - \\
II, n (\%) & $31(55.4 \%)$ & $73(57.9 \%)$ & 0.750 \\
III, n (\%) & $13(23.2 \%)$ & $28(22.2 \%)$ & 1.000 \\
IV, n (\%) & $12(21.4 \%)$ & $25(19.8 \%)$ & 0.840 \\
\hline Cardiogenic death, n (\%) & $0(0.0 \%)$ & $9(7.1 \%)$ & 0.059 \\
\hline Rehospitalization, n (\%) & $2(3.6 \%)$ & $27(21.4 \%)$ & 0.002 \\
Myocardial infarction, n(\%) & $1(1.8 \%)$ & $7(5.6 \%)$ & 0.438 \\
Heart failure, n (\%) & $1(1.8 \%)$ & $18(14.3 \%)$ & 0.008 \\
Stroke, n(\%) & $0(0.0 \%)$ & $2(1.6 \%)$ & 1.000 \\
& & & \\
\hline MACE, n (\%) & $2(3.6 \%)$ & $36(28.6 \%)$ & $<0.001$ \\
\hline
\end{tabular}

HFrEF: Heart failure with reduced ejection fraction, HFmrEF: Heart failure with mid-range ejection fraction, CR: Cardiac rehabilitation, NCR: Non cardiac rehabilitation, WBC: White blood cell, HGB: Hemoglobin, AST: Glutamic pyruvic transaminase, ALT: Glutamic pyruvic aminotransferase, HDL-C: High density lipoprotein cholesterol, non- HDL-C: non-High density lipoprotein cholesterol, TC: total cholesterol, FBS: Fasting blood sugar, EDLV: End diastolic diameter of left ventricle, EF: Ejection fraction, LM: The left main coronary artery, LAD: Left anterior descending branch, LCX: Left circumflex branch, RCA: Right coronary artery, MACE: major cardiac events, IQR: Interquartile range.

Table 3. Baseline characteristics of HFrEF patients 


\begin{tabular}{|c|c|c|c|}
\hline & Non-MACE $\square \mathrm{n}=31 \square$ & $\mathrm{MACE} \square \mathrm{n}=24 \square$ & $P$ \\
\hline Sex, male (\%) & $26(83.9 \%)$ & $17(70.8 \%)$ & 0.328 \\
\hline Age(years) & $59.90 \pm 8.24$ & $64.25 \pm 9.87$ & 0.081 \\
\hline History of hypertension, $\mathrm{n}(\%)$ & $18(58.1 \%)$ & $10(41.7 \%)$ & 0.282 \\
\hline History of diabetes, $n(\%)$ & $7(22.6 \%)$ & $11(45.8 \%)$ & 0.087 \\
\hline Smoking history, $n(\%)$ & $18(58.1 \%)$ & $12(50.0 \%)$ & 0.594 \\
\hline History of stroke, n (\%) & $4(12.9 \%)$ & $0(0.0 \%)$ & 0.123 \\
\hline WBC $\left(10^{9} / \mathrm{L}\right)$ & $9.43 \pm 3.16$ & $10.43 \pm 4.00$ & 0.306 \\
\hline Platelet $\left(10^{9} / \mathrm{L}\right)$ & $209.97 \pm 69.14$ & $199.58 \pm 76.70$ & 0.601 \\
\hline $\mathrm{HGB}(\mathrm{g} / \mathrm{l})$ & $140.39 \pm 19.80$ & $129.50 \pm 21.57$ & 0.057 \\
\hline Blood potassium(mmol/l) & $3.97 \pm 0.33$ & $4.40 \pm 0.54$ & 0.001 \\
\hline Urea nitrogen(mmol/l) & $6.26 \pm 1.82$ & $5.53 \pm 2.33$ & 0.196 \\
\hline Creatinine(umol/L), median (IQR) & $80.90(66.70,92.90)$ & $73.30(61.93,95.83)$ & 0.524 \\
\hline AST (U/L), median (IQR) & $89.70(25.20,363.70)$ & $144.75(28.43,380.45)$ & 0.333 \\
\hline ALT (U/L), median (IQR) & $49.20(26.10,70.10)$ & $55.15(22.33,126.3)$ & 0.297 \\
\hline HDL-C (mmol/l) & $1.13 \pm 0.23$ & $1.14 \pm 0.36$ & 0.936 \\
\hline non-HDL-C (mmol/l),median (IQR) & $3.31(2.93,4.79)$ & $3.29(2.36,3.88)$ & 0.135 \\
\hline TC (mmol/L), median (IQR) & $1.57(1.07,2.14)$ & $1.23(0.82,2.00)$ & 0.133 \\
\hline FBS (mmol/L), median (IQR) & $6.14(5.43,8.74)$ & $7.19(6.00,10.41)$ & 0.058 \\
\hline $\mathrm{EDLV}(\mathrm{mm})$ & $57.84 \pm 5.67$ & $54.00 \pm 5.96$ & 0.018 \\
\hline $\mathrm{EF}(\%)$, median (IQR) & $33.48 \pm 4.96$ & $33.58 \pm 4.71$ & 0.940 \\
\hline $\mathrm{CR}, \mathrm{n}(\%)$ & $18(58.1 \%)$ & $4(16.7 \%)$ & 0.002 \\
\hline
\end{tabular}

WBC: white blood cell, HGB: Hemoglobin, AST: Glutamic pyruvic transaminase, ALT: Glutamic pyruvic aminotransferase, HDL-C: High density lipoprotein cholesterol, non- HDL-C: non-High density lipoprotein cholesterol, TC: Total cholesterol, FBS: Fasting blood sugar, EDLV: End diastolic diameter of left ventricle, EF: Ejection fraction, CR: cardiac rehabilitation, MACE: major cardiac events, IQR: Interquartile range.

Table 4. Baseline characteristics of HFmrEF patients 


\begin{tabular}{|c|c|c|c|}
\hline & Non-MACE $\square \mathrm{n}=144 \square$ & $\mathrm{MACE} \square \mathrm{n}=38 \square$ & $\mathbf{P}$ \\
\hline Sex, male (\%) & $113(78.5 \%)$ & $22(57.9 \%)$ & 0.013 \\
\hline Age(years) & $57.69 \pm 11.64$ & $65.84 \pm 10.41$ & $<0.001$ \\
\hline History of hypertension, $\mathrm{n}(\%)$ & $70(48.6 \%)$ & $19(50 \%)$ & 1.000 \\
\hline History of diabetes, $n(\%)$ & $41(28.5 \%)$ & $9(23.7 \%)$ & 0.684 \\
\hline Smoking history, $\mathrm{n}(\%)$ & $90(62.5 \%)$ & $17(44.7 \%)$ & 0.063 \\
\hline History of stroke, n (\%) & $5(3.5 \%)$ & $5(13.2 \%)$ & 0.035 \\
\hline WBC $\left(10^{9} / \mathrm{L}\right)$ & $10.53 \pm 3.44$ & $9.73 \pm 2.64$ & 0.184 \\
\hline Platelet $\left(10^{9} / \mathrm{L}\right)$ & $218(181.75,250)$ & $231.5(186.5,262.25)$ & 0.365 \\
\hline $\mathrm{HGB}(\mathrm{g} / \mathrm{l})$ & $143.76 \pm 17.38$ & $135.63 \pm 18.44$ & 0.012 \\
\hline Blood potassium(mmol/l), median (IQR) & $3.98(3.66,4.17)$ & $4.12(3.89,4.41)$ & 0.009 \\
\hline Urea nitrogen(mmol/l), median (IQR) & $5.52(4.65,6.74)$ & $5.57(5.03,6.38)$ & 0.942 \\
\hline Creatinine(umol/L), median (IQR) & $67.85(57.20,79.40)$ & $74.40(58.40,85.88)$ & 0.213 \\
\hline AST (U/L), median (IQR) & $73.45(37.50,212.43)$ & $101.40(47.58,243.68)$ & 0.279 \\
\hline ALT (U/L), median (IQR) & $44.50(25.95,68.13)$ & $52.95(31.28,74.47)$ & 0.158 \\
\hline HDL-C(mmol/l) & $1.24 \pm 0.34$ & $1.27 \pm 0.38$ & 0.551 \\
\hline non-HDL-C(mmol/l),median (IQR) & $3.48(2.95,4.08)$ & $3.43(2.66,4.30)$ & 0.783 \\
\hline TC $(\mathrm{mmol} / \mathrm{L})$, median $(\mathrm{IQR})$ & $1.40(1.04,2.00)$ & $1.36(0.97,2.49)$ & 0.753 \\
\hline FBS $(\mathrm{mmol} / \mathrm{L})$, median $(\mathrm{IQR})$ & $6.54(5.21,9.18)$ & $6.62(5.88,9.61)$ & 0.162 \\
\hline $\operatorname{EDLV}(\mathrm{mm})$ & $51.52 \pm 5.10$ & $51.18 \pm 5.19$ & 0.719 \\
\hline $\mathrm{EF}(\%)$, median (IQR) & $46(44,49)$ & $46(42,47)$ & 0.095 \\
\hline CR, n (\%) & $54(37.5 \%)$ & $2(5.3 \%)$ & $<0.001$ \\
\hline
\end{tabular}

WBC: white blood cell, HGB: Hemoglobin, AST: Glutamic pyruvic transaminase, ALT: Glutamic pyruvic aminotransferase, HDL-C: High density lipoprotein cholesterol, non- HDL-C: non-High density lipoprotein cholesterol, TC: Total cholesterol, FBS: Fasting blood sugar, EDLV: End diastolic diameter of left ventricle, EF: Ejection fraction, CR: cardiac rehabilitation, MACE: major cardiac events, IQR: Interquartile range.

Table 5. Baseline characteristics of patients with cardiac rehabilitation 


\begin{tabular}{|c|c|c|c|}
\hline & Non-MACE $\square n=72 \square$ & $\mathrm{MACE} \square \mathrm{n}=6 \square$ & $P$ \\
\hline Sex, male (\%) & $49(68.1 \%)$ & $4(66 . .7 \%)$ & 1.000 \\
\hline Age(years) & $58.93 \pm 9.52$ & $52.33 \pm 6.95$ & 0.103 \\
\hline History of hypertension, $n(\%)$ & $39(54.2 \%)$ & $3(50.0 \%)$ & 1.000 \\
\hline History of diabetes, $n(\%)$ & $16(22.2 \%)$ & $4(66.7 \%)$ & 0.035 \\
\hline Smoking history, $n(\%)$ & $40(55.6 \%)$ & $4(66.7 \%)$ & 0.691 \\
\hline History of stroke, $n(\%)$ & $3(4.2 \%)$ & $0(0.0 \%)$ & 1.000 \\
\hline WBC $\left(10^{9} / \mathrm{L}\right)$, median (IQR) & $9.55(7.55,12.35)$ & $7.28(5.34,11.55)$ & 0.195 \\
\hline Platelet $\left(10^{9} / \mathrm{L}\right)$ & $230.4 \pm 64.39$ & $240.33 \pm 73.55$ & 0.721 \\
\hline $\mathrm{HGB}(\mathrm{g} / \mathrm{l})$ & $140.77 \pm 18.53$ & $134.00 \pm 21.68$ & 0.400 \\
\hline Blood potassium(mmol/l), median (IQR) & $3.96(3.66,4.17)$ & $4.31(3.96,4.63)$ & 0.043 \\
\hline Urea nitrogen(mmol/l) & $5.70 \pm 1.57$ & $5.30 \pm 1.11$ & 0.546 \\
\hline creatinine(umol/L), median (IQR) & $71.05(57.90,88.80)$ & $73.80(62.03,129.95)$ & 0.579 \\
\hline AST (U/L), median (IQR) & $70.35(29.43,203.52)$ & $70.50(33.60,167.83)$ & 0.751 \\
\hline ALT (U/L), median (IQR) & $41.40(23.30,65.30)$ & $66.25(35.38,102.98)$ & 0.111 \\
\hline $\mathrm{HDL}-\mathrm{C}(\mathrm{mmol} / \mathrm{l})$ & $1.17 \pm 0.25$ & $0.99 \pm 0.18$ & 0.106 \\
\hline non-HDL-C(mmol/l), median (IQR) & $3.48(3.01,4.18)$ & $3.51(3.01,4.39)$ & 1.000 \\
\hline TC (mmol/L), median (IQR) & $1.40(1.08,2.00)$ & $1.67(1.05,3.63)$ & 0.559 \\
\hline FBS (mmol/L) $\llbracket$ median (IQR) & $6.47(5.16,8.25)$ & $6.20(5.26,7.77)$ & 0.882 \\
\hline $\operatorname{EDLV}(\mathrm{mm})$ & $53.66 \pm 6.22$ & $55.33 \pm 5.28$ & 0.526 \\
\hline $\mathrm{EF}(\%)$, median (IQR) & $42(39,46)$ & $38.5(31.5,46.0)$ & 0.179 \\
\hline HFrEF, n (\%) & $51(70.8 \%)$ & $4(66.7 \%)$ & 1.000 \\
\hline \multicolumn{4}{|l|}{ KILLIP class } \\
\hline I, n (\%) & $0(0.0 \%)$ & $0(0.0 \%)$ & \\
\hline II, $\mathrm{n}(\%)$ & $34(47.2 \%)$ & $4(66.7 \%)$ & 0.425 \\
\hline III, $\mathbf{n}(\%)$ & $23(31.9 \%)$ & $2(33.3 \%)$ & 1.000 \\
\hline IV, n (\%) & $15(20.8 \%)$ & $0(0.0 \%)$ & 0.590 \\
\hline \multicolumn{4}{|l|}{ Target lesion location } \\
\hline LAD, n (\%) & $49(68.1 \%)$ & $2(33.3 \%)$ & 0.174 \\
\hline LCX, n (\%) & $3(4.2 \%)$ & $1(16.7 \%)$ & 0.279 \\
\hline RCA, n (\%) & $20(27.8 \%)$ & $3(50.0 \%)$ & 0.353 \\
\hline Rehospitalization, n (\%) & $0(0.0 \%)$ & $6(100.0 \%)$ & $<0.001$ \\
\hline
\end{tabular}




\begin{tabular}{|c|c|c|c|}
\hline Myocardial infarction, $\mathrm{n}(\%)$ & $0(0.0 \%)$ & $2(33.3 \%)$ & 0.005 \\
\hline Heart failure, $n(\%)$ & $0(0.0 \%)$ & $4(66.7 \%)$ & $<0.001$ \\
\hline Stroke, $n(\%)$ & $0(0.0 \%)$ & $0(0.0 \%)$ & - \\
\hline R-HR (bpm), median (IQR) & $72(67,81)$ & $79(56,90.5)$ & 0.751 \\
\hline E-HR(bpm), median (IQR) & $95(87,109)$ & 105.5(89.75,118.25) & 0.317 \\
\hline E-VE(L/min), median (IQR) & $28.95(25.45,34.00)$ & $30.95(22.88,35.42)$ & 0.913 \\
\hline$\Delta \mathrm{VE}(\mathrm{L} / \mathrm{min})$, median $(\mathrm{IQR})$ & $16.80(13.73,21.20)$ & $15.20(10.93,21.88)$ & 0.586 \\
\hline VE/MVV (\%), median (IQR) & $28(25.25,31.75)$ & $29.5(20.5,36.25)$ & 0.992 \\
\hline $\mathrm{VO}_{2}$ at $\mathrm{VT}(\mathrm{ml} / \mathrm{kg} / \mathrm{min})$, median (IQR) & $9(10,11)$ & $9(7.5,11)$ & 0.135 \\
\hline $\mathrm{E}-\mathrm{VCO}_{2}(\mathrm{~L} / \mathrm{min})$, median (IQR) & $0.70(0.61,0.85)$ & $0.64(0.47,0.82)$ & 0.383 \\
\hline$\Delta \mathrm{CO} 2(\mathrm{~L} / \mathrm{min})$, median (IQR) & $0.49(0.38,0.57)$ & $0.39(0.25,0.56)$ & 0.175 \\
\hline $\mathrm{VE} / \mathrm{VCO}_{2}$ slope, median (IQR) & $35.10(32.53,38.89)$ & $36.34(35.98,42.86)$ & 0.181 \\
\hline $\mathrm{R}-\mathrm{P}_{\mathrm{ET}} \mathrm{CO}_{2}(\mathrm{~mm} \mathrm{Hg})$, median (IQR) & $29(28,30)$ & $28(26.25,30.25)$ & 0.254 \\
\hline $\mathrm{P}_{\mathrm{ET}} \mathrm{CO}_{2}$ at $\mathrm{VT}(\mathrm{mm} \mathrm{Hg})$, median (IQR) & $33(32,34)$ & $32(29,33)$ & 0.016 \\
\hline$\Delta \mathrm{P}_{\mathrm{ET}} \mathrm{CO}_{2}(\mathrm{~mm} \mathrm{Hg})$, median (IQR) & $4(3,5)$ & $3(1.25,4.25)$ & 0.107 \\
\hline
\end{tabular}

WBC: White blood cell, HGB: Hemoglobin, AST: Glutamic pyruvic transaminase, ALT: Glutamic pyruvic aminotransferase, HDL-C: High density lipoprotein cholesterol, non- HDL-C: non-High density lipoprotein cholesterol, TC: total cholesterol, FBS: Fasting blood sugar, EDLV: End diastolic diameter of left ventricle, EF: Ejection fraction, HFrEF: Heart failure with reduced ejection fraction, LM: The left main coronary artery, LAD: Left anterior descending branch, LCX: Left circumflex branch, RCA: Right coronary artery, R-HR: Rest heart rate, E-HR: Exercise Heart Rate, E-VE: Exercise Minute ventilation, $\triangle \mathrm{VE}$ : Margin of Minute ventilation, VE/MVV\%: The ratio of minute ventilation to the maximum expected value, $\mathrm{VO}_{2}$ at VT: Oxygen consumption per kilogram of weight per minute at anaerobic threshold, $\mathrm{E}-\mathrm{VCO}_{2}$ : Exercise Carbon dioxide production, $\triangle \mathrm{VCO}{ }_{2}$ : Margin of Minute ventilation Carbon dioxide production, $\mathrm{VE} / \mathrm{VCO}_{2}$ slope: Minute ventilation/Carbon dioxide production, $\mathrm{R}-\mathrm{P}_{\mathrm{ET}} \mathrm{CO}$ : $\mathrm{Rest}$ Partial pressure of end-tidal carbon dioxide, $\mathrm{P}_{\mathrm{ET}} \mathrm{CO}_{2}$ at VT: Partial pressure of end-tidal carbon dioxide at anaerobic threshold, $\triangle \mathrm{P}_{\mathrm{ET}} \mathrm{CO}_{2}$ : Margin of Partial pressure of end-tidal carbon dioxide, MACE: major cardiac events, IQR: Interquartile range.

\section{Figures}






\section{Figure 1}

The Kaplan-Mayer curves of MACE-free survival in the HFrEF group. CR: cardiac rehabilitation, NCR: non cardiac rehabilitation, MACE: major cardiac events. 


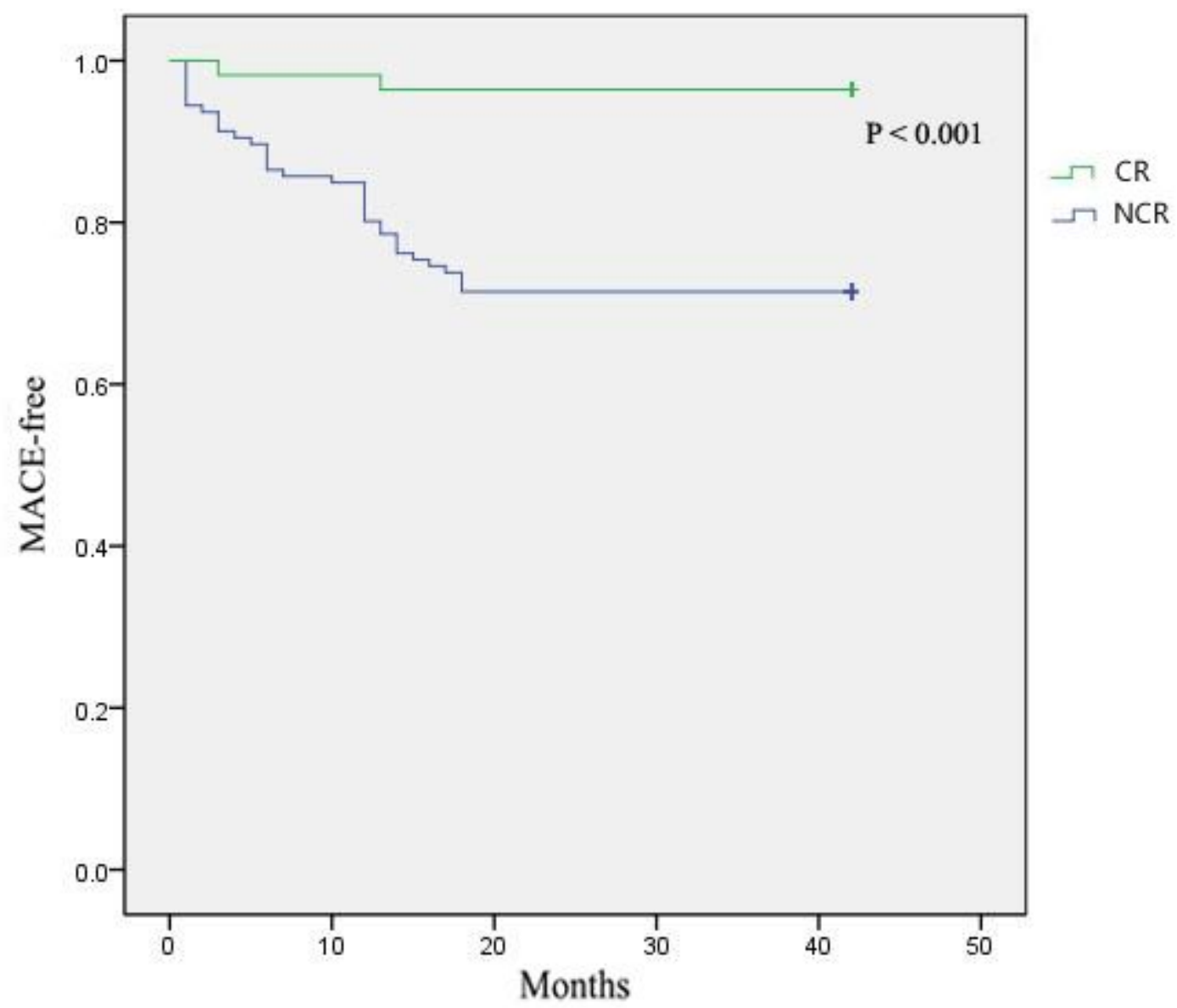

Figure 2

The Kaplan-Mayer curves of MACE-free survival in the HFmrEF group. CR: cardiac rehabilitation, NCR: non cardiac rehabilitation, MACE: major cardiac events. 


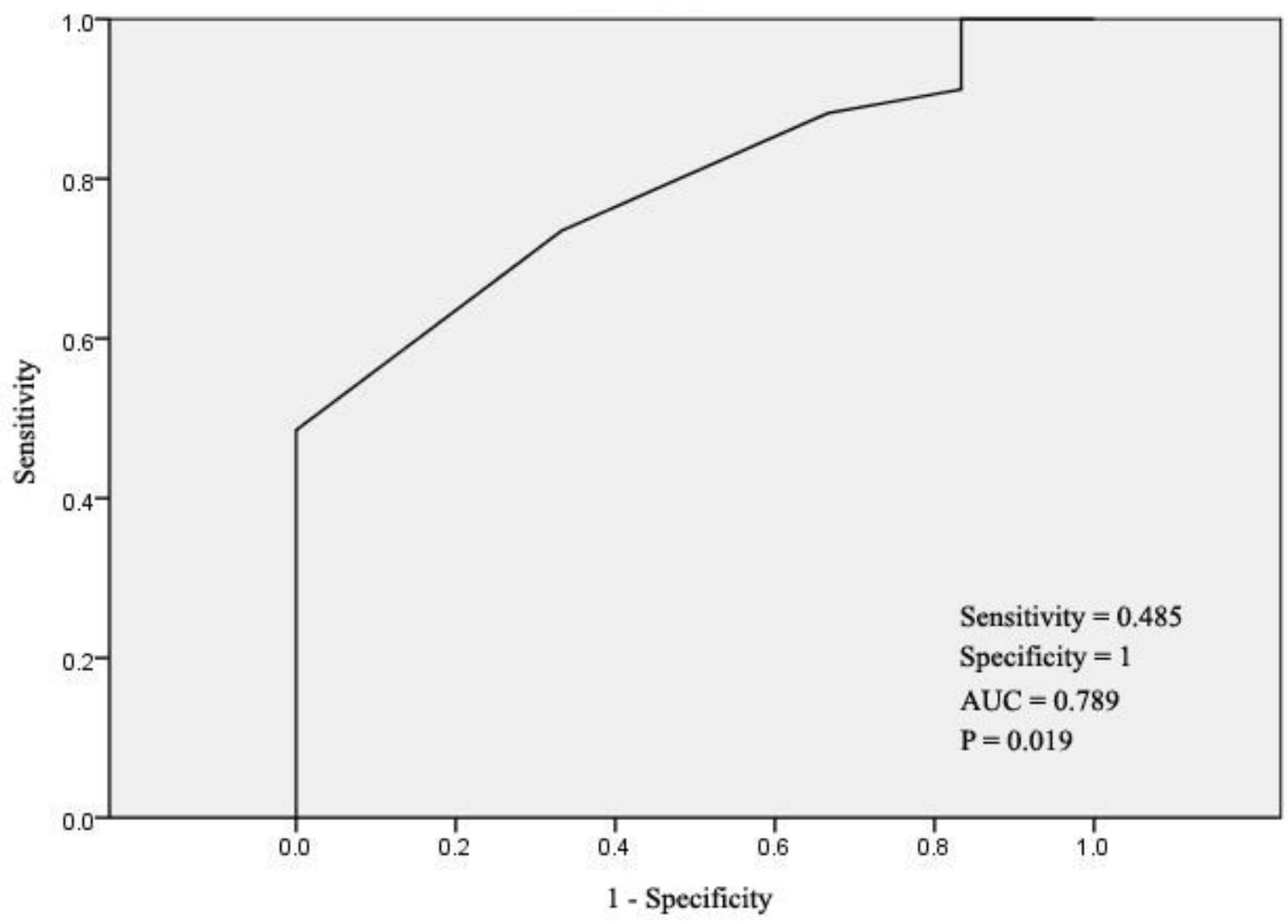

Figure 3

The ROC curve of PETCO2 at VT. PETCO2 at VT: Partial pressure of end-tidal carbon dioxide at anaerobic threshold. 


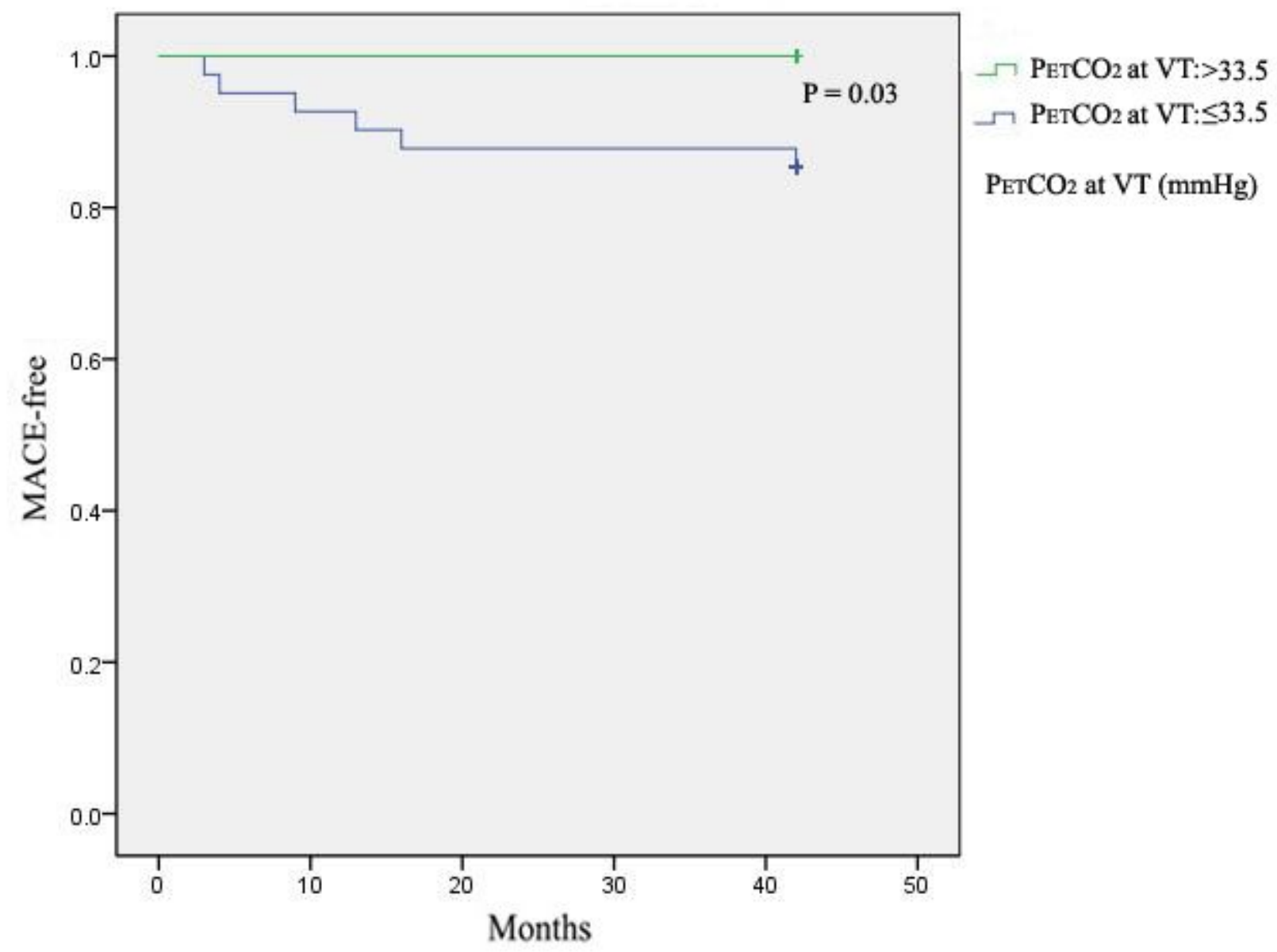

\section{Figure 4}

The Kaplan-Mayer curves of MACE-free survival in patients with rehabilitation. PETCO2 at VT: Partial pressure of end-tidal carbon dioxide at anaerobic threshold; MACE: major cardiac events. 